\title{
Nanoparticle diffusion in spontaneously expectorated sputum as a biophysical tool to probe disease severity in COPD
}

\author{
Jane F. Chisholm ${ }^{1,2}$, Siddharth K. Shenoy ${ }^{1,3}$, Julie K. Shade ${ }^{1,4}$, Victor Kim ${ }^{5}$, \\ Nirupama Putcha ${ }^{6}$, Kathryn A. Carson $\mathbb{1}^{7}$, Robert Wise $\mathbb{1}^{6}$, Nadia N. Hansel ${ }^{6}$, \\ Justin S. Hanes ${ }^{1,2,3,4,8}$, Jung Soo Suk ${ }^{1,2,3,8}$ and Enid Neptune ${ }^{6,8}$
}

Affiliations: ${ }^{1}$ Center for Nanomedicine, Wilmer Eye Institute, Johns Hopkins University School of Medicine, Baltimore, MD, USA. ${ }^{2}$ Dept of Chemical and Biomolecular Engineering, Johns Hopkins University, Baltimore, MD, USA. ${ }^{3}$ Dept of Ophthalmology, Wilmer Eye Institute, Johns Hopkins University School of Medicine, Baltimore, MD, USA. " Dept of Biomedical Engineering, Johns Hopkins University, Baltimore, MD, USA. ${ }^{5}$ Dept of Thoracic Medicine and Surgery, Temple University School of Medicine, Philadelphia, PA, USA. 'Division of Pulmonary and Critical Care Medicine, Johns Hopkins University School of Medicine, Baltimore, MD, USA. ${ }^{7}$ Dept of Epidemiology, Johns Hopkins University School of Medicine, Baltimore, MD, USA. ${ }^{8}$ Indicates equal contribution to this work.

Correspondence: Enid Neptune, Johns Hopkins School of Medicine, 1830 East Monument St., Room 547, Baltimore, MD 21205-2196, USA. E-mail: eneptunedjhmi.edu. Jung Soo Suk, Johns Hopkins University, 400 N. Broadway, Smith 6029, Baltimore, MD 21231, USA. E-mail: jsuk@jhmi.edu. Justin Hanes, Johns Hopkins University, 400 N. Broadway, Smith 6017, Baltimore, MD 21231, USA. E-mail: hanesवjhmi.edu.

@ERSpublications

Microstructural properties of COPD sputum probed by motility of $100 \mathrm{~nm}$ muco-inert particles correlate with disease severity characterised by pulmonary lung function http://bit.ly/2WOf7yF

Cite this article as: Chisholm JF, Shenoy SK, Shade JK, et al. Nanoparticle diffusion in spontaneously expectorated sputum as a biophysical tool to probe disease severity in COPD. Eur Respir J 2019; 54: 1900088 [https://doi.org/10.1183/13993003.00088-2019].

ABSTRACT Perturbations in airway mucus properties contribute to lung function decline in patients with chronic obstructive pulmonary disease (COPD). While alterations in bulk mucus rheology have been widely explored, microscopic mucus properties that directly impact on the dynamics of microorganisms and immune cells in the COPD lungs are yet to be investigated.

We hypothesised that a tightened mesh structure of spontaneously expectorated mucus (i.e. sputum) would contribute to increased COPD disease severity. Here, we investigated whether the mesh size of COPD sputum, quantified by muco-inert nanoparticle (MIP) diffusion, correlated with sputum composition and lung function measurements.

The microstructure of COPD sputum was assessed based on the mean squared displacement (MSD) of variously sized MIPs measured by multiple particle tracking. MSD values were correlated with sputum composition and spirometry. In total, 33 samples collected from COPD or non-COPD individuals were analysed.

We found that $100 \mathrm{~nm}$ MIPs differentiated microstructural features of COPD sputum. The mobility of MIPs was more hindered in sputum samples from patients with severe COPD, suggesting a tighter mucus mesh size. Specifically, MSD values inversely correlated with lung function.

These findings suggest that sputum microstructure may serve as a novel risk factor for COPD progression and severity. 


\section{Introduction}

Mucus abnormalities contribute to chronic morbidity in a variety of lung diseases, including chronic obstructive pulmonary disease (COPD) [1,2], cystic fibrosis (CF) [3] and asthma [4]. COPD is the third leading cause of death in the USA [5] and at least 30\% of people with COPD have chronic bronchitis (CB), characterised by chronic cough and sputum production $[6,7]$. In healthy lungs, mucus that lines the luminal surface of lung airways serves a critical protective purpose by trapping inhaled particulates and pathogens that are subsequently cleared from the airways via mucociliary clearance (MCC) [8-10]. However, in obstructive lung diseases, mucus hypersecretion can overwhelm MCC and results in bacterial overgrowth, chronic airway inflammation and airway obstruction [11]. Specifically in COPD, mucus hypersecretion is associated with accelerated lung function decline [12], increased hospitalisation rate and increased mortality [13]. Mucus obstruction of the small airways is also a significant predictive factor of COPD progression and mortality $[14,15]$, as well as exacerbation risk [16-18].

Airway mucus is a viscoelastic gel comprising a complex mixture of high molecular weight mucin glycoproteins, cells, cellular debris, bacterial proteins, antibacterial products and other molecules [19]. Alterations in the composition of mucus directly affect its biophysical properties, resulting in suboptimal MCC and subsequent disease manifestations [20]. In COPD patients with CB, there is enhanced expression of gel-forming mucins and elevated overall sputum solids content in the lumen of the small airways [21, 22]. Recently, ANDERSON et al. [23] found that increased solids content in sputum samples from $\mathrm{CB}$ patients correlated with elevated partial osmotic pressure of the mucus gel layer and impaired mucus clearance. Functional MCC is dependent on appropriate rheological properties of airway mucus [24]. Macro- (or bulk) rheological measurements have revealed an increased viscoelasticity of COPD sputum compared to samples from healthy subjects [25]. However, conventional bulk rheology measurements do not reveal microscopic properties of mucus or sputum, which significantly contribute to mucus physiology and may correlate with disease pathology [26].

The diffusion rate of variously sized nanoparticles has been employed as a biophysical tool to probe the microstructure of airway secretions [27-29], as well as other biological specimens, including the vitreous gel [30], brain extracellular matrix [31] and tumour tissues [32]. Compared to other methods, such as fluorescence recovery after photobleaching, multiple particle tracking (MPT) allows simultaneous tracking of hundreds of individual particles in highly complex and heterogeneous biological specimens at high spatiotemporal resolution, and quantification of individual particle transport rates [33]. We have previously shown that densely coating nanoparticle surfaces with polyethylene glycol (PEG) produces muco-inert nanoparticles (MIPs), also known as mucus-penetrating particles, that are capable of moving in human mucus secretions without being trapped by adhesive interactions [27-29, 34]. The diffusion of MIPs in mucus is thus primarily slowed by steric interaction imposed by the microstructure of the gel. In other words, MIPs of a given size will move more slowly in a mucus sample with a tighter mesh, especially if the MIP diameter approaches the average pore size of the mucus [27-29]. Conversely, conventional polymeric nanoparticles are trapped in mucus regardless of particle size due to adhesive interactions with mucus constituents; such particles are referred to as conventional particles or muco-adhesive particles (MAPs). In this study, we characterised MIP diffusion in spontaneously expectorated sputum from a cohort of cigarette smokers with and without airway obstruction to assess whether the sputum microstructure that governs MIP transport is associated with COPD disease severity and airway obstruction.

\section{Methods}

MIPs were prepared and characterised as previously described [28]. MPT was used to measure mean squared displacement (MSD) of fluorescently labelled MIPs and MAPs in freshly expectorated sputum samples from non-COPD smokers and COPD patients [33]. The per cent solids content of sputum was determined by weighing a given sample followed by freeze-drying and re-weighing the same sample. The concentrations of mucin and DNA in individual sputum samples were measured by fluorometric assays as previously described [28]. Statistical analyses were conducted using Wilcoxon signed rank test for paired comparisons, Wilcoxon rank sum test for two-sample comparisons and ANOVA or Kruskal-Wallis test for comparing more than two groups. Detailed experimental procedures are provided in the supplementary material.

\section{Results}

\section{Participant characteristics}

Demographic data were available for 33 participants: seven smokers without COPD, 18 patients with mild-moderate COPD (mCOPD) and eight patients with moderate-severe COPD (sCOPD) (table 1). All patients with COPD were current or former smokers. The transport analysis was conducted with sputum samples from 32 participants. Correlations between microstructure, biochemical composition and lung 


\begin{tabular}{lccc} 
TABLE 1 Participant demographics & & \\
& Non-COPD smoker & Mild-moderate COPD & Moderate-severe COPD $^{+}$ \\
\hline Subjects $\mathbf{n}$ & 7 & 18 & 8 \\
Age years & $56 \pm 2$ & $62 \pm 2$ & $70 \pm 3$ \\
Post-BD FEV1 \% pred & $95 \pm 7$ & $69 \pm 4$ & $39 \pm 2$ \\
FEV1/FVC & $0.97 \pm 0.02$ & $0.78 \pm 0.02$ & $0.5 \pm 0.04$ \\
Female & $3(43)$ & $9(49)$ & $1(17)$ \\
Current smoker & $5(71)$ & $12(67)$ & $4(67)$ \\
\hline
\end{tabular}

Data are presented as mean \pm SEM or $\mathrm{n}(\%)$, unless otherwise indicated. COPD: chronic obstructive pulmonary disease; $\mathrm{BD}$ : bronchodilator; $\mathrm{FEV}_{1}$ : forced expiratory volume in $1 \mathrm{~s}$; FVC: forced vital capacity. ${ }^{\#}$ : $F E V_{1} / F V C>0.7, F V C>$ lower limit of normal; ${ }^{\text {" }}$ : FEV $1 / F V C<0.7, F E V_{1}>50 \%$ pred; ${ }^{+}$: FEV $1 / F V C<0.7, F E V_{1}<50 \%$ pred.

function parameters were also applied to all 33 participants (including one participant's sample without MPT analysis).

\section{Transport of nanoparticles in spontaneously expectorated sputum from smokers without airway obstruction}

Nanoparticle movement in mucus approximates both the mesh "tightness" and the pore size within the mucus gel [28]. To establish whether differences in particle diameter and mucus adhesivity affected particle movement in sputum from non-COPD smokers, we first compared the transport behaviours of MIPs to those of similarly sized MAPs in spontaneously expectorated sputum samples from non-COPD smokers $(n=7)$. The dense PEG coating on the MIPs resulted in a slightly increased particle diameter and near neutral surface charge as measured by the $\zeta$-potential (table 2). For simplicity, we refer to nanoparticles based on their nominal sizes as reported in table 2. We also confirmed that, unlike MAPs, the muco-inert PEG coating effectively precluded adsorption of mucins on the surface of MIPs, confirming their muco-resistance (supplementary figure S1). We found that diffusion of MAPs, regardless of particle diameter, was largely hindered in sputum samples, as evidenced by the highly confined trajectories (figure 1a). In contrast, $100 \mathrm{~nm}$ MIPs rapidly moved through the sputum sample (supplementary movie S1), as evidenced by their diffusive trajectories (figure 1a). We further quantified diffusion rates of each particle type, as determined by MSD. The MSD represents the square of distance travelled by individual particles at a given time interval (i.e. time scale or $\tau$ ); thus, MSD is directly proportional to particle diffusion rate. Of note, we compared MSD values among different test groups at $\tau=1 \mathrm{~s}$ throughout the study, given the limited effects of both static and dynamic errors in particle tracking analysis at $\tau=1 \mathrm{~s}$ [33]. We found that $100 \mathrm{~nm}$ particles displayed a statistically significant difference in MSD between the MIPs and MAPs at $\tau=1 \mathrm{~s}$ (figure $1 \mathrm{~b}, \mathrm{p}<0.05$ ); in contrast, the differences were not significant for 300 and $500 \mathrm{~nm}$ particles (figure 1c, d). The tracking resolution was determined to be $\log _{10}\left(\mathrm{MSD}_{\tau=1 \mathrm{~s}}\right)$ of -3 based on the MSD values of particles immobilised in glue.

Transport of nanoparticles in spontaneously expectorated sputum from patients with COPD We next compared the diffusion of MAPs and MIPs in sputum samples collected from patients with COPD $(n \geqslant 13)$. Unlike $100 \mathrm{~nm}$ MAPs that showed highly confined trajectories, we found that the $100 \mathrm{~nm}$

\begin{tabular}{lcccc}
$\begin{array}{l}\text { TABLE 2 Nanoparticle physicochemical characterisation } \\
\text { Nominal size } \mathbf{n m}\end{array}$ & Particle type & Hydrodynamic diameter ${ }^{\#} \mathbf{n m}$ & PDI $^{\#}$ & $\zeta$-potential ${ }^{\text {ก }} \mathbf{~} \mathbf{V}$ \\
\hline $\mathbf{1 0 0}$ & MAP & $88 \pm 1$ & 0.02 & $-52 \pm 1$ \\
$\mathbf{1 0 0}$ & MIP & $109 \pm 2$ & 0.02 & $-7 \pm 1$ \\
$\mathbf{3 0 0}$ & MAP & $292 \pm 4$ & 0.01 & $-75 \pm 6$ \\
$\mathbf{3 0 0}$ & MIP & $318 \pm 7$ & 0.04 & $-4 \pm 1$ \\
$\mathbf{5 0 0}$ & MAP & $538 \pm 11$ & 0.05 & $-52 \pm 1$ \\
$\mathbf{5 0 0}$ & MIP & $553 \pm 5$ & 0.05 & $-4 \pm 1$
\end{tabular}

Data are presented as mean \pm SEM. PDI: polydispersity index; MAP: muco-adhesive particle; MIP: muco-inert nanoparticle. \#: measured in $10 \mathrm{mM} \mathrm{NaCl}$ at $\mathrm{pH} 7.4$ by dynamic light scattering; ${ }^{\text {ๆ: }}$ : measured in $10 \mathrm{mM}$ $\mathrm{NaCl}$ at $\mathrm{pH} 7.4$. 
FIGURE 1 Transport of mucoadhesive particles (MAPs) and muco-inert nanoparticles (MIPs) in spontaneously expectorated sputum from cigarette smokers without chronic obstructive pulmonary disease. a) Representative median trajectories of MAPs and MIPs possessing particle diameters of 100, 300 and $500 \mathrm{~nm}$. Trajectories show $15 \mathrm{~s}$ of motion. Scale bar $=2 \mu \mathrm{m}$. b-d) Median mean squared displacement (MSD) at a time scale of $1 \mathrm{~s}$ for MAPs and MIPs with diameters of $100 \mathrm{~nm}$ (b), $300 \mathrm{~nm}$ (c) and $500 \mathrm{~nm}$ (d). All data represent $\mathrm{n}=7$ sputum samples with at least 500 particles tracked per sample. Error bars represent SEM. *: $p<0.05$ (Wilcoxon signed rank test).
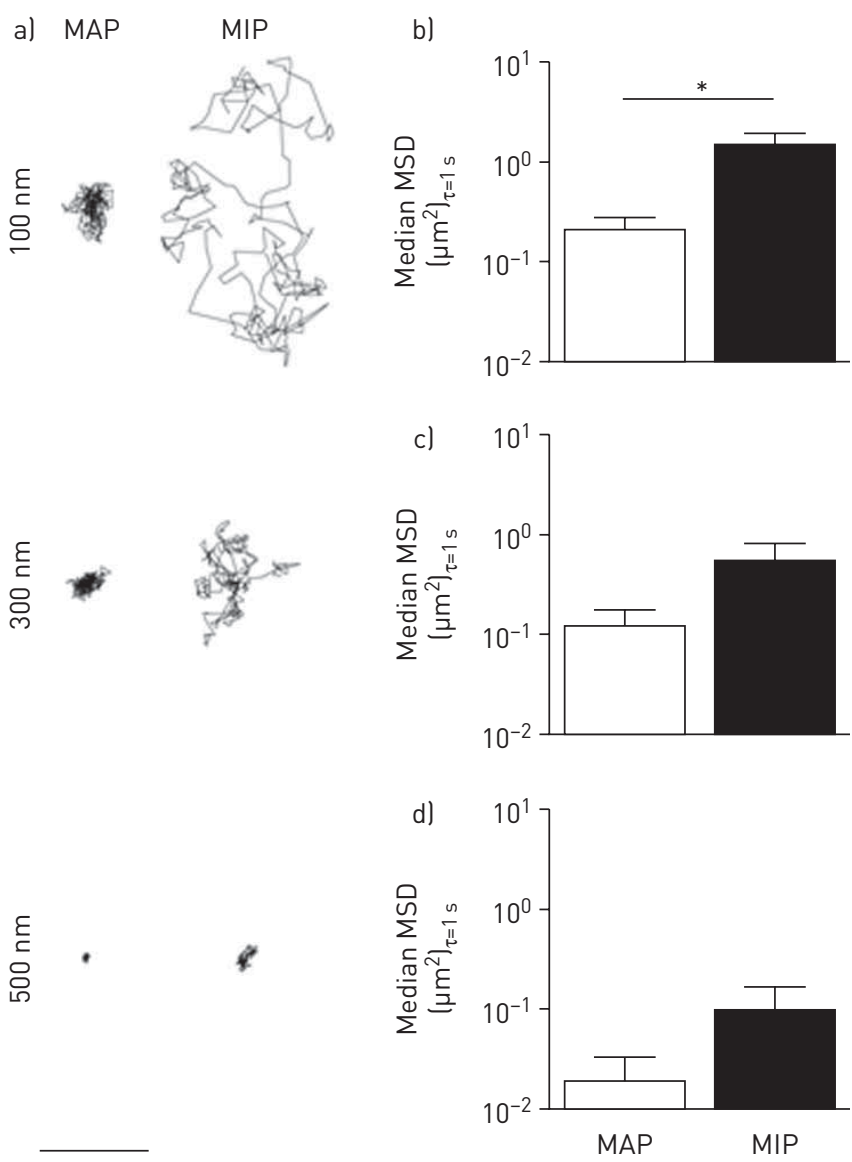

MIPs were capable of diffusing in sputum samples relatively unhindered (figure 2a). The MSD values were significantly greater for MIPs in comparison to MAPs (figure 2b). Similar to the observation with sputum samples from non-COPD smokers, both MAPs and MIPs possessing particle diameters $\geqslant 300 \mathrm{~nm}$ exhibited confined or highly hindered trajectories in COPD sputum samples (supplementary movie S2 for $300 \mathrm{~nm}$ MIPs and supplementary movie S3 for $500 \mathrm{~nm}$ MIPs). However, MSD values were significantly greater for 300 and $500 \mathrm{~nm}$ MIPs in comparison to the respective MAPs (figure $2 \mathrm{~b}, \mathrm{p}<0.05$ ), presumably due to the larger sample size compared to the studies with non-COPD smoker samples.

\section{Transport of individual MIPs in sputum samples from smokers without airway obstruction, with $m C O P D$ and with SCOPD}

We next analysed MSD values of individual MIPs with different particle sizes in sputum samples from non-COPD smokers and COPD patients. The diffusion rates of $100 \mathrm{~nm}$ MIPs, as measured by MSD, appeared to decrease with the increase in disease severity (non-COPD smoker $>$ mCOPD $>$ sCOPD; figure $3 a$ ). The difference was more pronounced when comparing the two extreme conditions of non-COPD smoker and SCOPD, as evidenced by the clear leftwards shift of the MSD distribution (i.e. greater fractions of MIPs with lower MSD values). In general, similar trends were observed with 300 and $500 \mathrm{~nm}$ MIPs where the fractions of rapidly moving particles (i.e. particles with high MSD values) tended to decrease with respect to disease severity (figure $3 \mathrm{~b}, \mathrm{c}$ ). However, $300 \mathrm{~nm}$ MIPs exhibited similar overall MSD distributions, as well as median MSD values, in sputum samples from non-COPD smokers and mCOPD patients, while the distribution in sCOPD samples was clearly leftwards-shifted (figure $3 \mathrm{~b}$ ). As expected from the larger particle diameters, the median MSD values of $500 \mathrm{~nm}$ MIPs were smaller than those of 100 and $300 \mathrm{~nm}$ MIPs by about an order of magnitude or more regardless of disease severity (figure 3c). In particular, the MSD values of a large fraction of $500 \mathrm{~nm}$ MIPs were below the tracking resolution $\left(\log _{10}\left(\mathrm{MSD}_{\tau=1 \mathrm{~s}}\right)<-3\right)$ or approaching it in sCOPD samples, which suggests that $500 \mathrm{~nm}$ MIPs are significantly larger than the sputum average pore size. We found that median MSD values, specifically $\log _{10}\left(\right.$ median $\mathrm{MSD}_{\tau=1 \mathrm{~s}}$ ), of $100 \mathrm{~nm}$ MIPs were able to distinguish disease severity, yielding a statistically significant difference between non-COPD smoker and sCOPD groups (supplementary figure S2a). However, $\log _{10}\left(\right.$ median $\mathrm{MSD}_{\tau=1 \mathrm{~s}}$ ) of larger MIPs were unable to do so (supplementary figure S2b, c). Of 
FIGURE 2 Transport of mucoadhesive particles (MAPs) and muco-inert nanoparticles (MIPs) in spontaneously expectorated sputum from chronic obstructive pulmonary disease patients. a) Representative trajectories of MAPs and MIPs possessing particle diameters of 100, 300 and $500 \mathrm{~nm}$. Trajectories show $15 \mathrm{~s}$ of motion. Scale bar $=2 \mu \mathrm{m}$. b-d) Median mean squared displacement (MSD) at a time scale of $1 \mathrm{~s}$ for MAPs and MIPs with diameters of $100 \mathrm{~nm}$ (b), $300 \mathrm{~nm}$ (c) and $500 \mathrm{~nm}$ (d). All data represent $n \geqslant 13$ sputum samples with at least 500 particles tracked per sample. Error bars represent SEM. **: $\quad p<0.01, \quad * * *$ : $\quad p<0.001$ (Wilcoxon signed rank test).
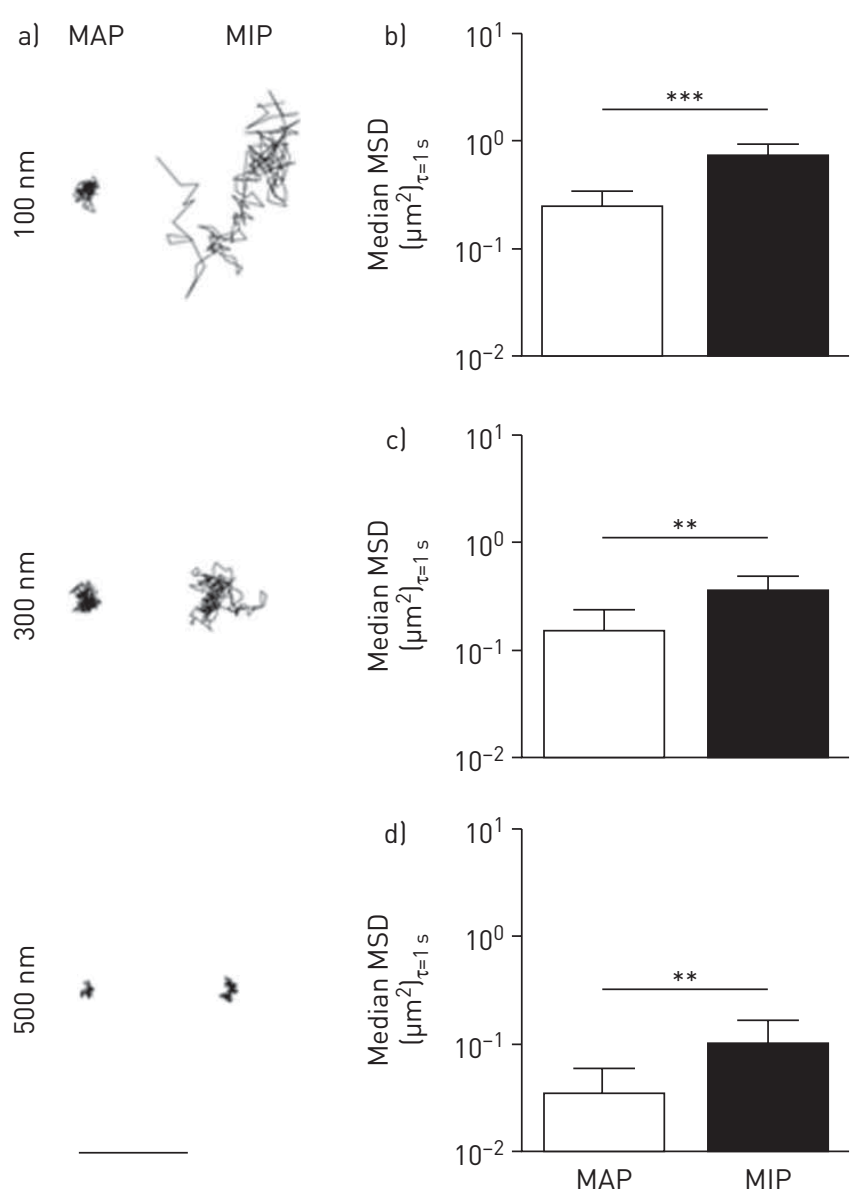

note, median MSD values of $100 \mathrm{~nm}$ MIPs were at least an order of magnitude greater than the tracking resolution regardless of disease severity, providing confidence in our measurement. We then confirmed that size-corrected median MSD values within each disease severity group did not exhibit statistically significant differences, suggesting that all probe particles experienced a similar microstructure regardless of particle size (supplementary figure S3).

In parallel, we conducted an identical analysis with differently sized MAPs. Whereas MSD distributions of $100 \mathrm{~nm}$ MAPs exhibited weaker but similar general trends to those of $100 \mathrm{~nm}$ MIPs (supplementary figure S4), disease severity could not be differentiated by the $\log _{10}$ (median $\mathrm{MSD}_{\tau=1 \mathrm{~s}}$ ) of $100 \mathrm{~nm}$ MAPs (supplementary figure S5a) nor $300 \mathrm{~nm}$ MAPs (supplementary figure S5b). An analysis of $\log _{10}\left(\mathrm{MSD}_{\tau=1 \mathrm{~s}}\right.$ ) of $500 \mathrm{~nm}$ MAPs unexpectedly revealed statistically significant differences between sCOPD versus non-COPD smoker or mCOPD groups (supplementary figure S5c). However, median MSD values of $500 \mathrm{~nm}$ MAPs measured in sputum samples from sCOPD patients were near the tracking resolution and thus these values cannot be reliably used to probe disease severity.

Based on all of these findings, subsequent microstructural analyses were conducted with $100 \mathrm{~nm}$ MIPs. We first utilised the measured MSD values of $100 \mathrm{~nm}$ MIPs, in conjunction with an obstruction-scaling model [28], to estimate pore sizes of sputum samples. As expected from the particle diffusion behaviours (figure 3), we found that the fractions of larger pores were clearly reduced with the increase in disease severity (supplementary figure S6).

\section{Sputum biochemical composition analysis}

We hypothesised that biochemical composition might affect the microstructural properties of sputum and, thus, we measured the macromolecular contents of the sputum samples. The per cent solids in the sputum collected ranged from $1.1 \%$ to $6.5 \%$ by weight, with the higher values primarily associated with more severe disease. The solids content for samples from non-COPD smokers $(n=7)$ and COPD patients $(n=26)$ was $2.5 \pm 0.5 \%$ and $3.1 \pm 0.2 \%$ on average, respectively, which is in agreement with previously published values [22]. Sputum from sCOPD patients exhibited the highest per cent solids content $(3.4 \pm 0.3 \%)$, while 
a)
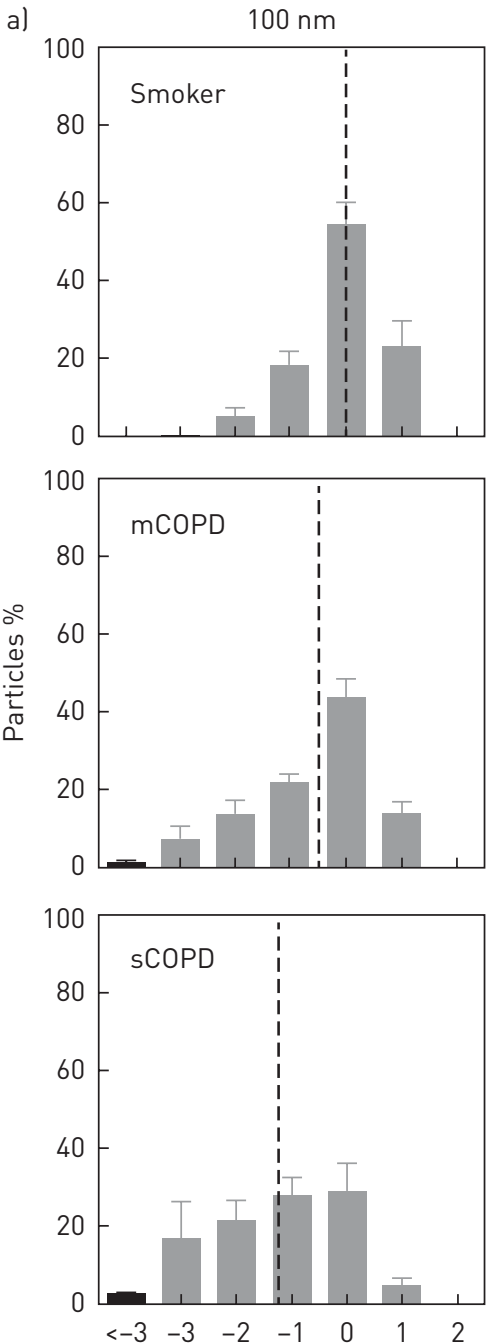

b)
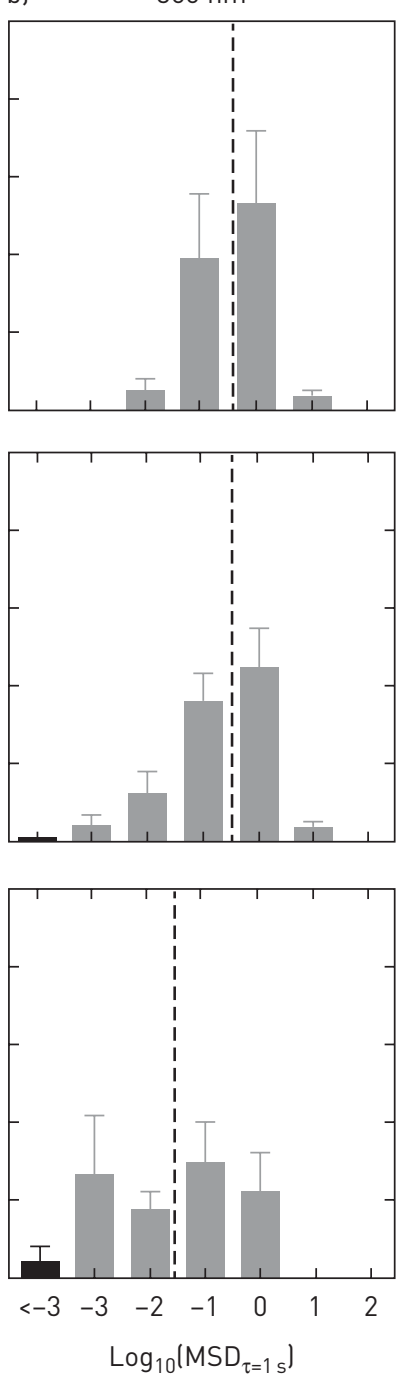

c)
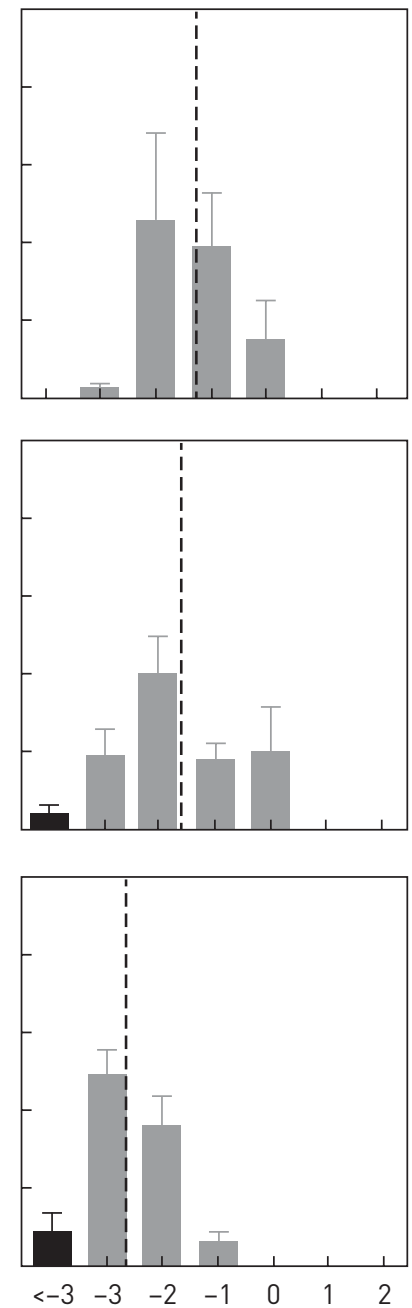

FIGURE 3 Transport of differently sized muco-inert nanoparticles (MIPs) in spontaneously expectorated sputum from smokers without chronic obstructive pulmonary disease (COPD) and COPD patients stratified for disease severity based on spirometric pulmonary function measurements. Subjects are categorised into one of the three groups, including non-COPD cigarette smokers (Smoker), mild COPD (mCOPD) and severe COPD (sCOPD). Distribution of the $\log _{10}\left(M D_{\tau=1 \mathrm{~s}}\right.$ ) of individual MIPs possessing particle diameters of a) $100 \mathrm{~nm}$, b) $300 \mathrm{~nm}$ and c) $500 \mathrm{~nm}$. All data represent $n \geqslant 5$ sputum samples with at least 500 particles tracked per sample. The median values of $\log _{10}\left(\mathrm{MSD}_{\tau=1} \mathrm{~s}\right)$ for each dataset are indicated by the dashed line. Black bars represent values below tracking resolution. MSD: mean squared displacement.

the per cent solids for non-COPD smoker and mCOPD samples were $2.5 \pm 0.5 \%$ and $3.0 \pm 0.3 \%$, respectively (figure $4 \mathrm{a}$ ). The per cent solids content values inversely correlated with the $\log _{10}\left(\right.$ median $\mathrm{MSD}_{\tau=1 \mathrm{~s}}$ ) of $100 \mathrm{~nm}$ MIPs (figure 5a; Spearman $\mathrm{r}=-0.73, \mathrm{p}<0.0001$ ).

We next measured concentrations of the primary macromolecules found in sputum, specifically mucin and DNA, and investigated whether they correlated with the diffusion rates of $100 \mathrm{~nm}$ MIPs. The mucin concentration was about 2 -fold greater in the amassed COPD sputum samples than that from non-COPD smokers $\left(5.5 \pm 0.76 \mathrm{mg} \cdot \mathrm{mL}^{-1}\right.$ and $2.9 \pm 0.6 \mathrm{mg} \cdot \mathrm{mL}^{-1}$, respectively). Specifically, the sCOPD cohort possessed the highest sputum mucin concentration at $8.4 \pm 1.9 \mathrm{mg} \cdot \mathrm{mL}^{-1}$, which was statistically significantly greater than that of both the non-COPD smoker $\left(3.0 \pm 0.6 \mathrm{mg} \cdot \mathrm{mL}^{-1}\right)$ and the $\mathrm{mCOPD}\left(4.4 \pm 0.6 \mathrm{mg} \cdot \mathrm{mL}^{-1}\right)$ groups (figure $4 \mathrm{~b}, \mathrm{p}<0.05$ ). However, the difference was not statistically significant between the non-COPD smoker and mCOPD groups. The DNA concentration was higher in amassed COPD sputum samples $\left(0.21 \pm 0.076 \mathrm{mg} \cdot \mathrm{mL}^{-1}\right)$ compared to the sample from non-COPD smokers $\left(0.07 \pm 0.01 \mathrm{mg} \cdot \mathrm{mL}^{-1}\right)$, but the differences were not statistically significant among different groups (figure 4c). When related to MIP diffusion, mucin concentration inversely correlated with the $\log _{10}\left(\right.$ median $\mathrm{MSD}_{\tau=1 \mathrm{~s}}$ ) of $100 \mathrm{~nm}$ MIPs 

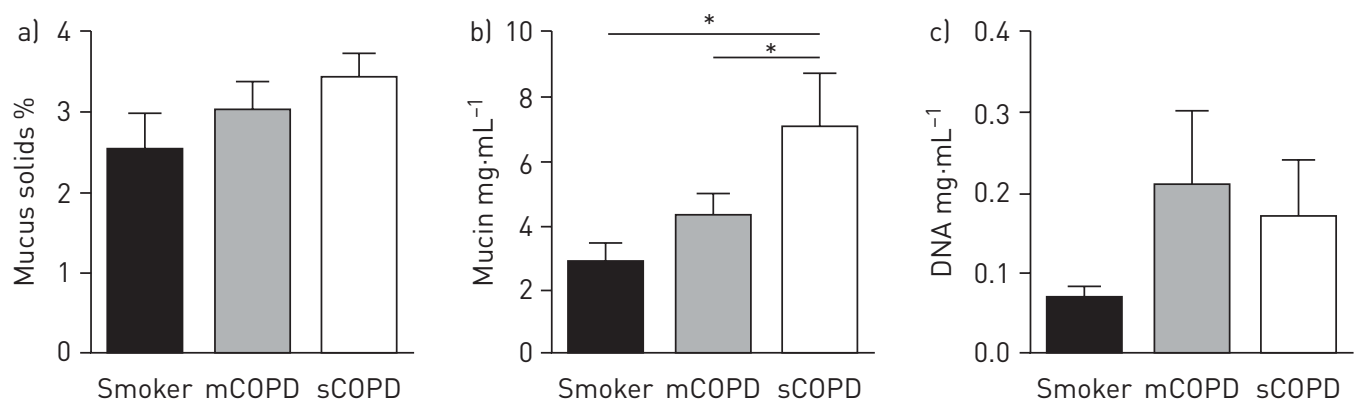

FIGURE 4 Sputum biochemical contents. Quantification of a) percentage of solids, b) mucin concentration and c) DNA concentration in sputum samples from smokers without chronic obstructive pulmonary disease (COPD) (Smoker) and patients with mild COPD (mCOPD) and severe COPD (sCOPD). Data represent $n \geqslant 29$ sputum samples. Error bars represent SEM. *: p<0.05 (ANOVA).

(figure 5b; $\mathrm{r}=-0.41, \mathrm{p}=0.03$ ); however, the relationship was not statistically significant for DNA content and $\log _{10}\left(\right.$ median $\mathrm{MSD}_{\tau=1 \mathrm{~s}}$ ) of $100 \mathrm{~nm}$ MIPs (figure $5 \mathrm{c} ; \mathrm{r}=-0.18, \mathrm{p}=0.36$ ).

\section{Relationship between lung function and microstructure}

We hypothesised that the altered sputum microstructure in COPD would correlate with impaired lung function. The $\log _{10}\left(\right.$ median $\mathrm{MSD}_{\tau=1 \mathrm{~s}}$ ) of $100 \mathrm{~nm}$ MIPs was positively correlated with the spirometric measurements of forced expiratory volume in $1 \mathrm{~s}(\mathrm{FEV} 1) /$ forced vital capacity (FVC) (figure 6a; $\mathrm{r}=0.41$, $\mathrm{p}=0.02$ ) and $\mathrm{FEV} 1 \%$ predicted (figure $6 \mathrm{~b} ; \mathrm{r}=0.41, \mathrm{p}=0.02$ ). We also compared the spirometric measurements to the solids content that has previously been assessed as a potential biomarker for lung function of $\mathrm{CB}$ patients [22]. Neither the FEV1 \% pred nor the FEV1/FVC \% pred significantly correlated with the sputum per cent solids (figure $6 c, d$ ).

\section{Discussion}

In this study, we examined whether sputum architecture, reflecting the pore size of spontaneously expectorated mucus gel, associates with COPD severity, lung function and sputum composition. To our knowledge, this is the first analysis of sputum microstructure in COPD patients. We specifically investigated the microstructural properties of spontaneously expectorated sputum from smokers with and without airway obstruction using MPT with MIP probes. We showed that dense surface coatings with low molecular weight PEG effectively prevented nanoparticle adhesion to sputum constituents, particularly mucins, similar to our observations with other mucus secretions, including cervicovaginal mucus [35], respiratory mucus [36], chronic rhinosinusitis mucus [37] and CF sputum [38]. We also demonstrated that the diffusion rates of MIPs with a particle diameter less than the average sputum mesh size $(100 \mathrm{~nm}$ MIPs in this case) can be used to distinguish key biophysical properties of sputum collected from patients with varying disease severity. We found that a tightened microstructure correlated with lung disease severity as indicated by a decrease in FEV1/FVC and FEV1. Finally, the mesh spacing (i.e. pore size) of the
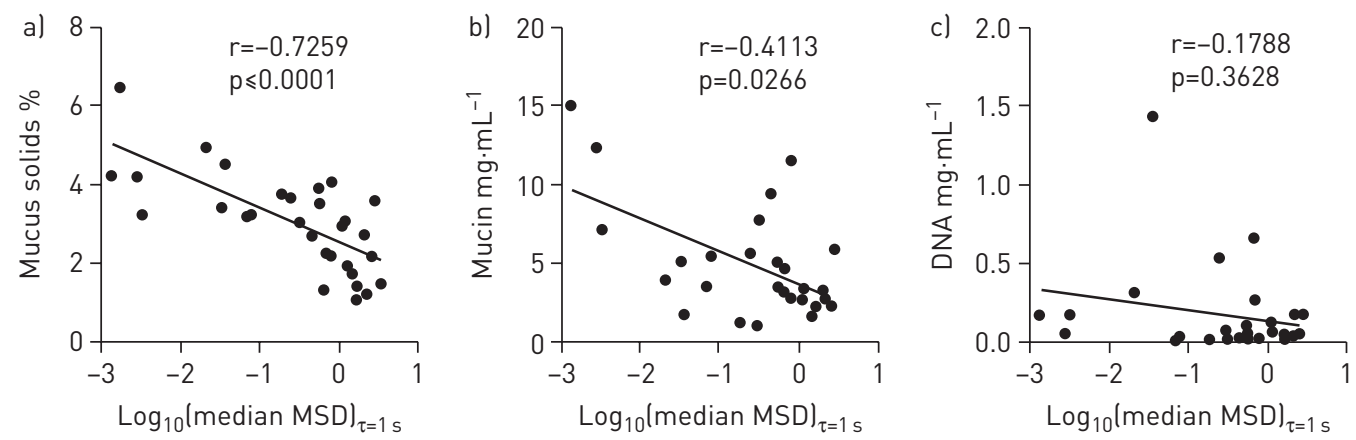

FIGURE 5 Relationships between sputum microstructure and biochemical components. $\log _{10}$ (median $\mathrm{MSD}_{\tau=1} \mathrm{~s}$ ) values of $100 \mathrm{~nm}$ muco-inert nanoparticles inversely correlate with a) per cent solids content and b) mucin concentration but not c) DNA concentration. Measurements were made for $n \geqslant 28$ individual, non-overlapping smokers without chronic obstructive pulmonary disease (COPD) and COPD patients. MSD: mean squared displacement. 
FIGURE 6 Relationships between sputum microstructure and spirometric measurements. $\log _{10}$ (median $M \mathrm{MS}_{\tau=1 \mathrm{~s}}$ ) values of $100 \mathrm{~nm}$ muco-inert nanoparticles positively correlate with a) the ratio of post-bronchodilator forced expiratory volume in $1 \mathrm{~s}$ (FEV 1 ) to forced vital capacity (FVC) and b) post-bronchodilator $\mathrm{FEV}_{1} \%$ pred, but the percentage of solids and c) $\mathrm{FEV}_{1} \%$ pred or d) FEV1 to FVC ratio were not correlated. Spirometry was performed on patients prior to sputum collection. Measurements were made for $n \geqslant 30$ individual, non-overlapping smokers without chronic obstructive pulmonary disease (COPD) and COPD patients. MSD: mean squared displacement.
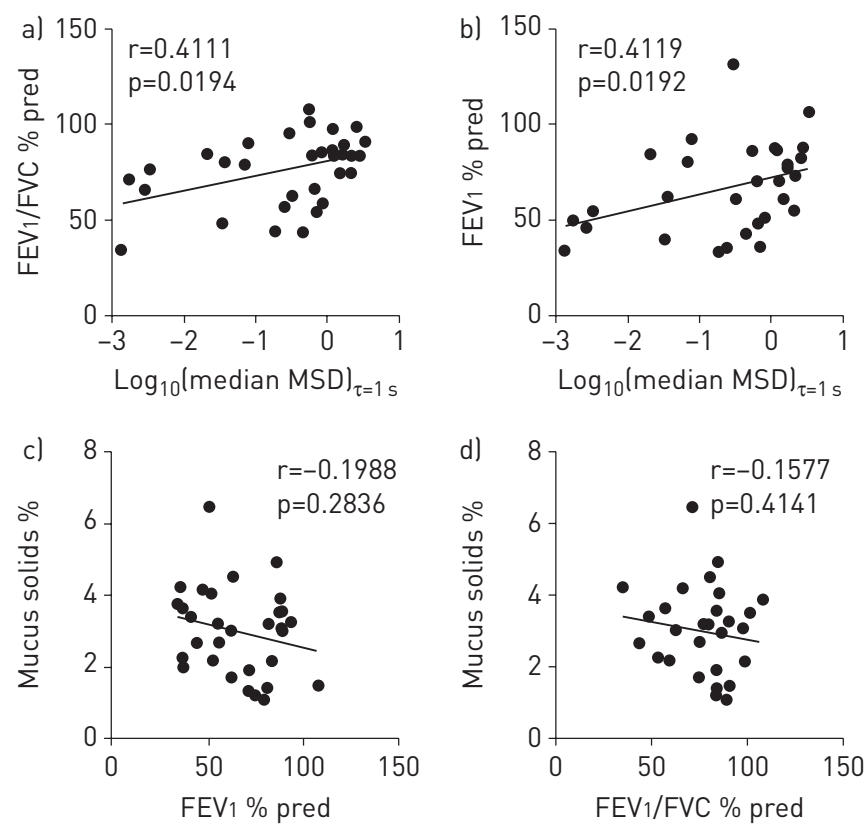

sputum network may impact the migration and/or colonisation of microorganisms [39, 40], including bacteria and viruses, and immune cells. If so, the mesh spacing measurement can potentially serve as a predictor of COPD-associated exacerbation, a critical risk factor for COPD progression [41].

Sputum is a gel that is composed of a complex porous network of solid strands of mucins, DNA and other molecules in an aqueous medium. In order to accurately perform microstructural analysis of the sputum mesh via MPT, the nanoparticle probes must be both non-adhesive and smaller than the average pore size in the sputum mesh [26]. Transport rates of MAPs are strongly affected by adhesive interactions with the sputum, whereas MIPs resist adhesive interactions with sputum constituents. Due to their muco-inert nature, MIP movement is primarily affected by steric hindrance imposed by the sputum mesh, which makes MIPs uniquely appropriate for use in examination of unperturbed sputum architecture, such as mesh spacing. We found that $100 \mathrm{~nm}$ MIPs travelled relatively unhindered through the porous sputum samples freshly obtained from both non-COPD smokers and COPD patients. In contrast, $500 \mathrm{~nm}$ MIPs, despite their muco-inert surfaces, did not diffuse rapidly in sputum because they were too large to fit through the sputum pores. These findings indicate that $100 \mathrm{~nm}$ MIPs are optimal to probe the sputum microstructure, whereas conventional MAPs of any size and MIPs larger than the average opening size in the sputum mesh are not suitable for this application.

Biophysical properties of COPD sputum have been relatively underexplored compared to biochemical content analysis, including quantification of pro-inflammatory and bacterial cell markers $[42,43]$. Previous biophysical analysis of sputum samples collected from patients with obstructive lung diseases primarily focused on measurement and comparison of macro-rheological properties; as an example, the degree of purulence, an indication of infection, correlates with bulk viscoelasticity of CF sputum [25]. However, these conventional rheological measurements do not provide direct information on sputum microarchitecture $[33,44]$. By combining MIPs and the MPT technique to probe sputum microstructure, we discovered a significant correlation between diffusion of $100 \mathrm{~nm}$ MIPs and disease stage, specifically between sputum samples from non-COPD smokers and SCOPD patients. The reduction in MIP diffusion rates, as quantified by $\log _{10}\left(\right.$ median $\mathrm{MSD}_{\tau=1 \mathrm{~s}}$ ), indicates that the sputum mesh (i.e. pore size) is tighter in sputum samples from patients with more advanced COPD.

Consistent with previous reports [22, 23], we found a modest increase in the per cent solids content of sputum samples from COPD patients, especially sCOPD, compared with that of non-COPD smokers. We found an inverse correlation between per cent solids and the MIP $\log _{10}\left(\right.$ median $\mathrm{MSD}_{\tau=1} \mathrm{~s}$ ), suggesting that a greater solids concentration, as can occur with sputum dehydration [23] or mucin hypersecretion, contributes to a tighter sputum mesh in severe COPD. This agrees with a previous report where in vitro particle diffusion rates in mucus inversely correlated with solids content [22]. However, this study was conducted with large $(1 \mu \mathrm{m})$, non-PEGylated (muco-adhesive) particles and, thus, the diffusion readout is more relevant to bulk rheological mucus properties than to microstructural properties such as pore size [45]. 
Many believe that airway inflammation in obstructive lung disease is linked to perturbation of mucin [46] and/or DNA content [47], which results in elevation of mucus elasticity [8,48]. We found that the mucin concentration was significantly increased in sputum samples collected from COPD patients compared to those from non-COPD smokers. This is in agreement with a recently published paper that demonstrated that the total mucin concentration was significantly higher in induced sputum from patients diagnosed with $\mathrm{CB}$ than from those without $\mathrm{CB}$ [49]. Indeed, we found that the increased mucin concentration corresponded with a tighter sputum microstructure in this study. The pore size of the mucus mesh can potentially be affected by the cross-linking density of mucin fibres [48, 50]. YUAN et al. [48] recently reported that oxidation arising from airway inflammation increases the number of disulfide crosslinks of mucin polymers and, thus, increases the stiffness/elasticity of CF sputum. Increased oxidative stress is also a hallmark of COPD-associated lung disease [51, 52]. We also note that other biochemical properties, including $\mathrm{pH}$ and salt composition, may affect molecular arrangements of macromolecules, thereby impacting on mucus biophysical properties [53, 54].

We found for the first time that sputum microstructural properties correlated with lung function measures (i.e. $\mathrm{FEV}_{1} / \mathrm{FVC}$ and $\mathrm{FEV}_{1} \%$ pred) in COPD. In $\mathrm{CF}$ sputum, altered sputum rheological properties correlate with bacterial colonisation and reduced lung function [55]. The tighter mesh in COPD sputum may also provide a permissive environment for chronic infection and inflammation, perhaps due to reduced bacteria and neutrophil migration coupled with reduced MCC [39]. Thus, microstructure readouts based on MIP diffusion in sputum may inform the study of disease progression and/or clinical exacerbations. Importantly, there is not a significant relationship between lung function and per cent solids, potentially limiting the solids content as a biomarker for COPD severity. Further, the microstructure analysis may also be implemented as a readout in therapeutic trials to evaluate airway-directed therapies, including mucolytic and mucus-hydrating agents [56]. Finally, our findings invite further analysis of the molecular interactions that contribute to pore size, such as disulfide cross-linking, oxidative modifications and mucin-macromolecule interactions. Microstructure measurements can only be performed on fresh, spontaneously expectorated sputum so as to preserve the physiological structure and to prevent deterioration observed with prolonged storage or freezing [28]. Induced sputum samples were not used because dilution by inhaled saline during the collection process may alter the physiological microstructure. Thus, the COPD patient population sampled with this method is constrained by the ability to generate a spontaneous specimen.

Overall, our findings suggest that the characterisation of sputum microstructure, available with spontaneous but not induced sputum samples, may provide novel insights into the specific properties of mucus that contribute to COPD pathogenesis. Future studies will focus on the examination of sputum architecture in larger longitudinal cohorts with detailed clinical, physiological and functional readouts. Such studies could further support the use of sputum mesh size as a predictive and personalised index of disease state and progression.

Acknowledgements: The authors thank the SPIROMICS participants and participating physicians, investigators and staff for making this research possible. More information about the study and how to access SPIROMICS data is available at www.spiromics.org. We would like to acknowledge the following current and former investigators of the SPIROMICS sites and reading centres: Neil E. Alexis, Wayne H. Anderson, R. Graham Barr, Eugene R. Bleecker, Richard C. Boucher, Russell P. Bowler, Elizabeth E. Carretta, Stephanie A. Christenson, Alejandro P. Comellas, Christopher B. Cooper, David J. Couper, Gerard J. Criner, Ronald G. Crystal, Jeffrey L. Curtis, Claire M. Doerschuk, Mark T. Dransfield, Christine M. Freeman, MeiLan K. Han, Nadia N. Hansel, Annette T. Hastie, Eric A. Hoffman, Robert J. Kaner, Richard E. Kanner, Eric C. Kleerup, Jerry A. Krishnan, Lisa M. LaVange, Stephen C. Lazarus, Fernando J. Martinez, Deborah A. Meyers, John D. Newell Jr, Elizabeth C. Oelsner, Wanda K. O’Neal, Robert Paine, III, Nirupama Putcha, Stephen I. Rennard, Donald P. Tashkin, Mary Beth Scholand, J. Michael Wells, Robert A. Wise and Prescott G. Woodruff. The project officers from the Lung Division of the National Heart, Lung, and Blood Institute were Lisa Postow and Thomas Croxton.

Conflict of interest: J.F. Chisholm has nothing to disclose. S.K. Shenoy has nothing to disclose. J.K. Shade has nothing to disclose. V. Kim reports personal fees for peer review from Medscape, personal fees for advisory board work from CSA Medical, Concert Pharmaceuticals, Gala Therapeutics, AstraZeneca and Boehringer Ingelheim, personal fees for chairing meetings from ABIM Critical Care Testwriting Committee, and grants from NHLBI (K23HL094696), outside the submitted work. N. Putcha reports grants from NIH/NHLBI (K23), outside the submitted work. K.A. Carson has nothing to disclose. R. Wise reports grants and personal fees for data monitoring committee work and consultancy from AstraZeneca/Medimmune and GSK, grants and personal fees for data monitoring and steering committee work from Boehringer Ingelheim, personal fees for clinical end-point committee work from Contrafect, personal fees for data safety monitoring committee work from Pulmonx, personal fees for data monitoring committee work from Roche/Genentech and Merck, personal fees for steering committee work from Spiration, personal fees for chairing workshops from Sunovion, grants from Pearl Therapeutics, personal fees for consultancy from Circassia, Pneuma, Verona, Denali, Aradigm, Mylan, Theravance and Propeller Health, and personal fees for safety review committee work from Bonti and Kiniksa, outside the submitted work. N.N. Hansel reports grants and personal fees for advisory board work from AstraZeneca and GSK, grants from Boehringer Ingelheim, NIH and COPD Foundation, and personal fees for advisory board work from Mylan, outside the submitted work. J.S. Hanes reports grants from NIH, during the conduct of the 
study. The muco-inert particle technology described in this publication is being developed by Kala Pharmaceuticals. J.S. Hanes declares a financial, a management/advisor, and a paid consulting relationship with Kala Pharmaceuticals; is a cofounder of Kala Pharmaceuticals and owns company stock, which is subject to certain restrictions under Johns Hopkins University policy. J.S. Suk reports grants from NIH, during the conduct of the study. E. Neptune has nothing to disclose.

Support statement: This work was supported by the National Institutes of Health (R01HL127413 and R01HL125169) and the Cystic Fibrosis Foundation. The content is solely the responsibility of the authors and does not necessarily represent the official views of the National Institutes of Health. SPIROMICS was supported by contracts from the NIH/NHLBI (HHSN268200900013C, HHSN268200900014C, HHSN268200900015C, HHSN268200900016C, HHSN268200900017C, HHSN268200900018C HHSN268200900019C, HHSN268200900020C), which were supplemented by contributions made through the foundation for the NIH from AstraZeneca; Bellerophon Pharmaceuticals; Boehringer Ingelheim Pharmaceuticals, Inc; Chiesi Farmaceutici SpA; Forest Research Institute, Inc; GSK; Grifols Therapeutics, Inc; Ikaria, Inc; Nycomed GmbH; Takeda Pharmaceutical Company; Novartis Pharmaceuticals Corporation; Regeneron Pharmaceuticals, Inc; and Sanofi. Funding information for this article has been deposited with the Crossref Funder Registry.

\section{References}

1 Rogers DF. Mucus hypersecretion in chronic obstructive pulmonary disease. Novartis Found Symp 2001; 234: 65-83.

2 Cerveri I, Brusasco V. Revisited role for mucus hypersecretion in the pathogenesis of COPD. Eur Respir Rev 2010; 19: $109-112$.

3 Kreda SM, Davis CW, Rose MC. CFTR, mucins, and mucus obstruction in cystic fibrosis. Cold Spring Harb Perspect Med 2012; 2: a009589.

4 Evans CM, Kim K, Tuvim MJ, et al. Mucus hypersecretion in asthma: causes and effects. Curr Opin Pulm Med 2009; 15: 4-11.

$5 \quad$ Hoyert DL, Xu J. Deaths: preliminary data for 2011. Natl Vital Stat Rep 2012; 61: 1-51.

6 Kim V, Han MK, Vance GB, et al. The chronic bronchitic phenotype of COPD: an analysis of the COPDGene Study. Chest 2011; 140: 626-633.

7 Marsh SE, Travers J, Weatherall M, et al. Proportional classifications of COPD phenotypes. Thorax 2008; 63: 761-767.

8 Fahy JV, Dickey BF. Airway mucus function and dysfunction. N Engl J Med 2010; 363: 2233-2247.

9 Knowles MR, Boucher RC. Mucus clearance as a primary innate defense mechanism for mammalian airways. J Clin Invest 2002; 109: 571-577.

10 Schneider CS, Xu Q, Boylan NJ, et al. Nanoparticles that do not adhere to mucus provide uniform and long-lasting drug delivery to airways following inhalation. Sci Adv 2017; 3: e1601556.

11 Danahay H, Jackson AD. Epithelial mucus-hypersecretion and respiratory disease. Curr Drug Targets Inflamm Allergy 2005; 4: 651-664.

12 Allinson JP, Hardy R, Donaldson GC, et al. The Presence of chronic mucus hypersecretion across adult life in relation to COPD development. Am J Respir Crit Care Med 2015; 192: 943-950.

13 Vestbo J, Prescott E, Lange P. Association of chronic mucus hypersecretion with FEV1 decline and chronic obstructive pulmonary disease morbidity. Copenhagen City Heart Study Group. Am J Respir Crit Care Med 1996; 153: 1530-1535.

14 Hogg JC, Chu F, Utokaparch S, et al. The nature of small-airway obstruction in chronic obstructive pulmonary disease. N Engl J Med 2004; 350: 2645-2653.

15 Hogg JC, Chu FS, Tan WC, et al. Survival after lung volume reduction in chronic obstructive pulmonary disease: insights from small airway pathology. Am J Respir Crit Care Med 2007; 176: 454-459.

16 Burgel PR, Nesme-Meyer P, Chanez P, et al. Cough and sputum production are associated with frequent exacerbations and hospitalizations in COPD subjects. Chest 2009; 135: 975-982.

17 Corhay JL, Vincken W, Schlesser M, et al. Chronic bronchitis in COPD patients is associated with increased risk of exacerbations: a cross-sectional multicentre study. Int J Clin Pract 2013; 67: 1294-1301.

18 Hurst JR, Vestbo J, Anzueto A, et al. Susceptibility to exacerbation in chronic obstructive pulmonary disease. N Engl J Med 2010; 363: 1128-1138.

19 Williams OW, Sharafkhaneh A, Kim V, et al. Airway mucus: from production to secretion. Am J Respir Cell Mol Biol 2006; 34: 527-536.

20 Randell SH, Boucher RC. Effective mucus clearance is essential for respiratory health. Am J Respir Cell Mol Biol 2006; 35: 20-28.

21 Caramori G, Di Gregorio C, Carlstedt I, et al. Mucin expression in peripheral airways of patients with chronic obstructive pulmonary disease. Histopathology 2004; 45: 477-484.

22 Hill DB, Vasquez PA, Mellnik J, et al. A biophysical basis for mucus solids concentration as a candidate biomarker for airways disease. PLoS One 2014; 9: e87681.

23 Anderson WH, Coakley RD, Button B, et al. The relationship of mucus concentration (hydration) to mucus osmotic pressure and transport in chronic bronchitis. Am J Respir Crit Care Med 2015; 192: 182-190.

24 Giordano AM, Holsclaw D, Litt M. Mucus rheology and mucociliary clearance: normal physiologic state. Am Rev Respir Dis 1978; 118: 245-250.

25 Serisier DJ, Carroll MP, Shute JK, et al. Macrorheology of cystic fibrosis, chronic obstructive pulmonary disease \& normal sputum. Respir Res 2009; 10: 63.

26 Lai SK, Wang YY, Wirtz D, et al. Micro- and macrorheology of mucus. Adv Drug Deliv Rev 2009; 61: 86-100.

27 Duncan GA, Jung J, Hanes J, et al. The mucus barrier to inhaled gene therapy. Mol Ther 2016; 24: 2043-2053.

28 Duncan GA, Jung J, Joseph A, et al. Microstructural alterations of sputum in cystic fibrosis lung disease. JCI Insight 2016; 1: e88198.

29 Suk JS, Xu Q, Kim N, et al. PEGylation as a strategy for improving nanoparticle-based drug and gene delivery. Adv Drug Deliv Rev 2016; 99:28-51.

$30 \mathrm{Xu}$ Q, Boylan NJ, Suk JS, et al. Nanoparticle diffusion in, and microrheology of, the bovine vitreous ex vivo. J Control Release 2013; 167: 76-84. 
31 Nance EA, Woodworth GF, Sailor KA, et al. A dense poly(ethylene glycol) coating improves penetration of large polymeric nanoparticles within brain tissue. Sci Transl Med 2012; 4: 149ra119.

32 Nance E, Zhang C, Shih TY, et al. Brain-penetrating nanoparticles improve paclitaxel efficacy in malignant glioma following local administration. ACS Nano 2014; 8: 10655-10664.

33 Schuster BS, Ensign LM, Allan DB, et al. Particle tracking in drug and gene delivery research: state-of-the-art applications and methods. Adv Drug Deliv Rev 2015; 91: 70-91.

34 Mastorakos P, da Silva AL, Chisholm J, et al. Highly compacted biodegradable DNA nanoparticles capable of overcoming the mucus barrier for inhaled lung gene therapy. Proc Natl Acad Sci USA 2015; 112: 8720-8725.

35 Lai SK, O'Hanlon DE, Harrold S, et al. Rapid transport of large polymeric nanoparticles in fresh undiluted human mucus. Proc Natl Acad Sci USA 2007; 104: 1482-1487.

36 Schuster BS, Suk JS, Woodworth GF, et al. Nanoparticle diffusion in respiratory mucus from humans without lung disease. Biomaterials 2013; 34: 3439-3446.

37 Lai SK, Suk JS, Pace A, et al. Drug carrier nanoparticles that penetrate human chronic rhinosinusitis mucus. Biomaterials 2011; 32: 6285-6290.

38 Suk JS, Lai SK, Wang YY, et al. The penetration of fresh undiluted sputum expectorated by cystic fibrosis patients by non-adhesive polymer nanoparticles. Biomaterials 2009; 30: 2591-2597.

39 Matsui H, Verghese MW, Kesimer M, et al. Reduced three-dimensional motility in dehydrated airway mucus prevents neutrophil capture and killing bacteria on airway epithelial surfaces. J Immunol 2005; 175: 1090-1099.

40 Bansil R, Celli JP, Hardcastle JM, et al. The influence of mucus microstructure and rheology in Helicobacter pylori infection. Front Immunol 2013; 4: 310.

41 Ramsey SD, Hobbs FD. Chronic obstructive pulmonary disease, risk factors, and outcome trials: comparisons with cardiovascular disease. Proc Am Thorac Soc 2006; 3: 635-640.

42 Paone G, Conti V, Vestri A, et al. Analysis of sputum markers in the evaluation of lung inflammation and functional impairment in symptomatic smokers and COPD patients. Dis Markers 2011; 31: 91-100.

43 Bartoli ML, Di Franco A, Vagaggini B, et al. Biological markers in induced sputum of patients with different phenotypes of chronic airway obstruction. Respiration 2009; 77: 265-272.

44 Ensign LM, Schneider C, Suk JS, et al. Mucus penetrating nanoparticles: biophysical tool and method of drug and gene delivery. Adv Mater 2012; 24: 3887-3894.

45 Mason TG, Ganesan K, vanZanten JH, et al. Particle tracking microrheology of complex fluids. Phys Rev Lett 1997; 79: 3282-3285.

46 Hauber HP, Foley SC, Hamid Q. Mucin overproduction in chronic inflammatory lung disease. Can Respir J 2006; 13: $327-335$.

47 Wright TK, Gibson PG, Simpson JL, et al. Neutrophil extracellular traps are associated with inflammation in chronic airway disease. Respirology 2016; 21: 467-475.

48 Yuan S, Hollinger M, Lachowicz-Scroggins ME, et al. Oxidation increases mucin polymer cross-links to stiffen airway mucus gels. Sci Transl Med 2015; 7: 276 ra227.

49 Kesimer M, Ford AA, Ceppe A, et al. Airway mucin concentration as a marker of chronic bronchitis. $N$ Engl J Med 2017; 377: 911-922.

50 Nielsen H, Hvidt S, Sheils CA, et al. Elastic contributions dominate the viscoelastic properties of sputum from cystic fibrosis patients. Biophys Chem 2004; 112: 193-200.

51 Repine JE, Bast A, Lankhorst I. Oxidative stress in chronic obstructive pulmonary disease. Oxidative Stress Study Group. Am J Respir Crit Care Med 1997; 156:341-357.

52 Kirkham PA, Barnes PJ. Oxidative stress in COPD. Chest 2013; 144: 266-273.

53 Tang XX, Ostedgaard LS, Hoegger MJ, et al. Acidic pH increases airway surface liquid viscosity in cystic fibrosis. J Clin Invest 2016; 126: 879-891.

54 Wang YY, Lai SK, Ensign LM, et al. The microstructure and bulk rheology of human cervicovaginal mucus are remarkably resistant to changes in pH. Biomacromolecules 2013; 14: 4429-4435.

55 Tomaiuolo G, Rusciano G, Caserta S, et al. A new method to improve the clinical evaluation of cystic fibrosis patients by mucus viscoelastic properties. PLoS One 2014; 9: e82297.

56 Braga PC, Allegra L, Bossi R, et al. Identification of subpopulations of bronchitic patients for suitable therapy by a dynamic rheological test. Int J Clin Pharmacol Res 1989; 9: 175-182. 